\title{
Detection of high-risk human papillomavirus DNA in sentinel lymph nodes of patients with cervical cancer
}

\author{
YAN LU, XUN XU, XIU-HONG NONG and DE-SHENG YAO \\ Department of Gynecological Oncology, Affiliated Tumor Hospital of Guangxi Medical University, \\ Nanning, Guangxi 530000, P.R. China
}

Received March 7, 2019; Accepted October 25, 2019

DOI: $10.3892 / \mathrm{ol} .2020 .11337$

\begin{abstract}
The aim of the present study was to investigate the expression of human papillomavirus (HPV) DNA in sentinel lymph nodes (SLN) in patients with early-stage cervical cancer (CC). In addition, the present study compared the positive rate of SLNs metastasis detected by routine pathological examination, and investigated the value of HPV-DNA in the detection of early CC lymph node micrometastasis. Reverse transcription-quantitative PCR (RT-qPCR) was used in order to evaluate the HPV DNA detection in all CC samples [International Federation of Gynecology and Obstetrics (FIGO) stage IA2-IIA2]. The consistency of HPV-DNA was compared between primary lesions and SLNs. The positive rates of HPV-DNA were compared with pathological diagnosis of SLN metastasis, and the association between the positive expression of HPV-DNA in SLNs and the clinical and pathological parameters of patients with cervical cancer were analyzed. A total of 345 sentinel lymph nodes were detected in 100 patients with IA2-IIA2 CC. The positive rates of RT-qPCR and conventional histopathological detection of SLNs metastasis were $31.6 \%$ (109/345) and 12.8\% (44/345), respectively $(\mathrm{P}<0.001)$. The positive expression of HPV-DNA in SLNs was associated with the clinical stage and tumor diameter $(\mathrm{P}<0.05)$, but not with patients' age, depth of cervical invasion, histological grade, lymphatic and vascular space invasion (LVSI), squamous cell carcinoma antigen (SCCAg) $(\mathrm{P}>0.05)$. The detection of HPV-DNA expression in pelvic lymph nodes of early CC may be used to improve the detection rate of micrometastasis, guide the postoperative adjuvant therapy more accurately and improve prognosis. Patients with positive HPV-DNA would require closer surveillance than those with negative HPV-DNA.
\end{abstract}

Correspondence to: Professor De-Sheng Yao, Department of Gynecological Oncology, Affiliated Tumor Hospital of Guangxi Medical University, 71 Hedi Road, Nanning, Guangxi 530000, P.R. China

E-mail: yaodesheng@gxmu.edu.cn

Key words: human papillomavirus-DNA, micrometastasis, cervical cancer, sentinel lymph node

\section{Introduction}

Lymph node metastasis (LNM) is an independent risk factor affecting the prognosis of patients with cervical cancer (CC). Accurate determination of LNM in patients with early $\mathrm{CC}$ is of great significance for guiding individualized adjuvant therapy and improving the prognosis (1). Although the LNM rate of early stage CC (IA1-IB1) is only $0.0-29.3 \%$ (2), the recurrence rate remains of $15 \%$ in patients without LNM (3). Lentz et al (3) used immunohistochemistry (IHC) to assess 3,106 lymph nodes from 132 patients with pathologically negative lymph nodes, and reported that micrometastases can be found in $15 \%$ patients with early stage cervical cancer who were considered as lymph node negative by conventional histologic analysis. This is due to the failure of traditional pathological methods to diagnose the micro-metastasis of lymph nodes (4), and the fact that detection of micro-metastasis of lymph nodes requires highly specific biomarkers, such as cytokeratin, squamous cell carcinoma antigen (SCC) and human papilloma virus (HPV) (5). However, IHC or cytokeratin are considered less specific $(6,7)$. The high-risk human papilloma virus (HR-HPV) DNA is considered a useful biological tool for detecting the lymph node micrometastases in patients with CC $(8,9)$. Previous studies have reported the prevalence of HPV-DNA in both pelvic lymph nodes and para-aortic lymph nodes; however, these studies have used different laboratory methods, clinical environments and measurements (10-12). Dürst et al (13) demonstrated, via reverse transcription-quantitative PCR (RT-qPCR), that HPV16-E6-E7-mRNA is more sensitive and specific than cytokeratin-(CK)19-mRNA for the detection of disseminated tumor cells in sentinel lymph nodes (SLNs). The present study demonstrated that HPV16-E6-E7-mRNA improved the diagnostic rate of micrometastasis and thus concluded it to be a valuable tool for evaluating prognosis (13). RNA can be easily degraded without RT; however, its stability increases following RT into cDNA. DNA is the product sequence amplified, and RT fluorescence qPCR methods can improve the sensitivity and specificity (9). The present study used RT-qPCR in order to search for HPV16/18 DNA sequences in SLNs and to evaluate the association between HPV and lymph node micrometastasis of CC, as well as to investigate its clinical significance. 


\section{Materials and methods}

Patient information. The SLNs were collected from 100 patients at the Department of Gynecologic Oncology at the Affiliated Tumor Hospital of Guangxi Medical University (Nanning, China) between August 2017 and August 2018. The inclusion criteria met by all patients were as follows: i) Preoperative cervical biopsy pathological diagnosis was confirmed as invasive carcinoma (squamous, adenocarcinoma or adenosquamous carcinoma); ii) International Federation of Gynecology and Obstetrics (FIGO) stage (14) was IIA2-IIA; iii) cervical fluid-based cytology HPV test was performed prior to surgery (HC-2 method), including tests for HR HPV type 17 (HPV16, -18, -31, -33, -35, -39, -45, -51, -52, -53, -56, $-58,-59,-66,-68,-82$ and -83$)$; and iv) the complete data of clinical cases were collected. The exclusion criteria were as follows: i) Patients who underwent previous cervical treatment (Loop Electrosurgical Excision Procedure and cone excision); ii) the imaging findings indicated marked retroperitoneal lymph node metastasis or distant metastasis; and iii) patients who received preoperative radiotherapy. The present study was approved by The Medical Ethics Committee of Guangxi Medical University Affiliated Tumor Hospital (registration number, LW2018028). Written consent was obtained from all patients prior to sample collection.

Identification of SLN. Prior to surgery, the patients were placed in the lithotomy position and were anesthetized. The normal cervix around the tumor was injected with $1 \mathrm{ml}$ of carbon nanoparticles (CNP) at 3 and 9 o'clock, with a deep $(0.3 \pm 0.5 \mathrm{~cm})$ cervical injection. The injection process lasted for at least $3 \mathrm{~min}$, following which pressure was applied locally to prevent the CNP extravasation after the injection. During surgery, lymph nodes staining in the drainage field of the pelvic lymph system were identified. The lymph nodes that stained within 15 min of injection were defined as SLNs, whilst those remaining were classed as non-SLNs (nSLNs). Subsequently, the SLNs were removed and the tumor position was recorded and counted. Following detection of the SLNs, patients underwent laparoscopic radical hysterectomy + pelvic lymphadenectomy (with or without para-aortic lymph node sampling). The same surgical group of physicians performed the surgery. These physicians were gynecologists of the affiliated tumor hospital of Guangxi medical university, and were from the same operation group of the surgeon who operated.

Specimen collection. Following collection of the SLNs, the fresh tissue was cut into $3 \mathrm{~mm}$ thick sections. The samples were then transferred into tagged sterile EP tubes without RNA enzymes, and stored at $-80^{\circ} \mathrm{C}$. Other specimens were labeled and sent for routine pathological examination.

Reagents and primers. The following reagents were purchased from Takara Biotechnology Co., Ltd. Tissue RNA extraction kits (Takara MiniBEST Universal RNA Extraction Kit PrimeScript $^{\mathrm{TM}}$ ), transcriptional Master Mix (Perfect Real Time, SYBR ${ }^{\circledR}$ ) and RT-PCR reagents (Premix Ex Taq TM II Perfect Real Time).

The following primer pairs were used for the RT-qPCR: HPV16-mRNA: Forward: 5'-AAGGGCGTAACCGAAATC
GGT-3' and reverse: 5'-GTTTGCAGCTCTGTGCATA-3'; amplified fragments $141 \mathrm{bp}$. HPV18-mRNA: Forward, 5'-CAT TTTGTGAACAGGCAGAGC-3' and reverse: 5'-ACTTGT GCATCATTGTGGACC-3'; and GAPDH: Forward: 5'-CGG AGTCAACGGATTTGGTCGTAT-3' and reverse: 5'-AGC CTTCTCCATGGTGGTGAAGAC-3'.

RNA extraction. HPV-DNA was selected for extraction from SLNs under sterile RNase-free conditions to prevent RNA degradation, according to the manufacturer's protocol. The total RNA was measured using a nucleic acid protein analyzer (NanoDropND-2000 micrometer; NanoDrop Technologies; Thermo Fisher Scientific, Inc.). Specimens with $\mathrm{A}_{260 / 280}$ values between 1.8-2.1 were of good purity. Specimens with high integrity and purity were subjected to RT in order to synthesize cDNA. cDNA reaction system for reverse transcription synthesis was as follows: 5x PrimeScript RTMaster Mix $\mathrm{x} 1$ (for RealTime) $4.0 \mu \mathrm{l}+\mathrm{RNA}$ 4.0-12.0 $\mu \mathrm{l}$ (depending on RNA concentration) $+\mathrm{RNaseFree} \mathrm{dH}_{2} \mathrm{O}$ to $20.0 \mu \mathrm{l}$ at $37^{\circ} \mathrm{C}$ for $15 \mathrm{~min}$ (reverse transcription reaction), $85^{\circ} \mathrm{C}$ for $5 \mathrm{sec}$ (deactivation reaction of reverse transcriptase), at $4^{\circ} \mathrm{C}$ for $4-5 \mathrm{~min}$, and finally stored at $-20^{\circ} \mathrm{C}$.

$R T-q P C R$. The total reaction system was $20 \mu 1$, which included $2.0 \mu \mathrm{l}$ cDNA, $0.8 \mu \mathrm{l}$ sense and anti-sense primers, $10.0 \mu \mathrm{l}$ SYBR $^{\circledR}$ Premix Ex Taq ${ }^{\mathrm{TM}}$ II, $0.4 \mu 1$ ROX Reference Dye (50x) and $20.0 \mu 1$ distilled $\mathrm{H}_{2} \mathrm{O}$. The follow PCR cycle was applied: Stage 1, predenaturation at $95^{\circ} \mathrm{C}$ for $30 \mathrm{sec}$ and for 1 cycle; stage $2, \mathrm{PCR}$ reaction at $95^{\circ} \mathrm{C}$ for $5 \mathrm{sec}, 60^{\circ} \mathrm{C}$ for $30-34 \mathrm{sec}$, and for 40 cycles in total. The target genome, the internal reference genome and the 2-tube negative control (with sterile distilled water instead of cDNA) were set for each amplification. Each experiment was performed in triplicate.

Agarose gel electrophoresis. Agarose $(1 \mathrm{~g})$ was mixed with $50 \mathrm{ml}$ 0.5X TBE buffer to make 5\% agarose gel. DNA marker and PCR products were loaded into the wells and electrophoresis was performed at $100 \mathrm{~V}$ for $50 \mathrm{~min}$. Following electrophoresis, the gel was removed and the results were recorded using a color analyzer. Each experiment was performed in triplicate. The expression of HPV-DNA in SLNs was analyzed, using 50-500 bp DNA markers as a reference standard. The DNA sequence amplified by PCR was compared with the HPV16 and HPV18 DNA in the gene bank (HPV 16 sequence, https://www. ncbi.nlm.nih.gov/nucleotide/KY994539.1?report=genbank\&lo $\mathrm{g} \$=$ nuclalign\&blast_rank=94\&RID=XRTDTSNB016; HPV18 sequence, https://www.ncbi.nlm.nih.gov/nucleotide/MF288722.1?report=genbank\&log $\$=$ nuclalign\&blast_rank= $3 \& \mathrm{RID}=\mathrm{XRS4T07H014)}$ for Blast sequence alignment.

Judgement and relative quantitative analysis of positive results. The reaction system and reaction conditions were as follows: $20 \mu 1$ of total reaction system containing $1.0 \mu 1$ of cDNA template, $0.8 \mu 1$ HPV16 and HPV18 gene sense and anti-sense primers each, $10.0 \mu \mathrm{l}$ of SYBR ${ }^{\circledR}$ Premix Ex Taq ${ }^{\mathrm{TM}}$ II, $0.4 \mu 1$ of ROX Reference Dye (50x) and $20.0 \mu 1$ of distilled $\mathrm{H}_{2} \mathrm{O}$. The reaction conditions were as follows: Stage 1, predenaturation at $95^{\circ} \mathrm{C}$ for $30 \mathrm{sec}$ and for 1 cycle; stage 2, PCR reaction at $95^{\circ} \mathrm{C}$ for $5 \mathrm{sec}, 60^{\circ} \mathrm{C}$ for $30 \mathrm{sec}$, and for 40 cycles in total; stage $3,95^{\circ} \mathrm{C}$ for $15 \mathrm{sec}$ and for 1 cycle; predenaturation 
Table I. Demographics and tumor factors.

\begin{tabular}{|c|c|}
\hline Characteristics & No. of cases, $n$ \\
\hline \multicolumn{2}{|l|}{ Histology } \\
\hline Squamous cell carcinoma & 78 \\
\hline Adenocarcinoma & 20 \\
\hline Adenosquamous carcinoma & 2 \\
\hline \multicolumn{2}{|l|}{ Tumor grading } \\
\hline G1 & 8 \\
\hline G2 & 27 \\
\hline $\mathrm{G} 3$ & 51 \\
\hline Uncategorized & 14 \\
\hline \multicolumn{2}{|l|}{ Stage } \\
\hline IA2 & 0 \\
\hline IB1 & 32 \\
\hline IB2 & 24 \\
\hline IIA1 & 21 \\
\hline IIA2 & 23 \\
\hline \multicolumn{2}{|l|}{ Tumor size } \\
\hline$<2 \mathrm{~cm}$ & 19 \\
\hline $2-4 \mathrm{~cm}$ & 45 \\
\hline$>4 \mathrm{~cm}$ & 36 \\
\hline \multicolumn{2}{|l|}{ Depth of invasion } \\
\hline$<1 / 3$ & 28 \\
\hline $1 / 3-2 / 3$ & 30 \\
\hline$>2 / 3$ & 42 \\
\hline Vaginal margin positive & 0 \\
\hline Lymphovascular space invasion & 30 \\
\hline Neoadjuvant chemotherapy & 18 \\
\hline \multicolumn{2}{|l|}{ HPV infection } \\
\hline Yes & 92 \\
\hline No & 8 \\
\hline
\end{tabular}

at $94^{\circ} \mathrm{C}$ for $5 \mathrm{~min}$, followed by $30 \mathrm{sec}$ at $94^{\circ} \mathrm{C}, 1 \mathrm{~min}$ at $55^{\circ} \mathrm{C}$, and $1 \mathrm{~min}$ at $72^{\circ} \mathrm{C}$ for a total of 40 cycles, and finally extended at $72^{\circ} \mathrm{C}$ for $10 \mathrm{~min}$. Samples were stored at $4^{\circ} \mathrm{C}$. Following the reaction, the fluorescence reaction curve was automatically obtained by software TOWER3G 3.4 (Analytik Jena AG), and the amplification efficiency and cycle threshold value (15) of each reaction system were calculated. Each experiment was performed in triplicate.

Pathological examination. SLNs were fixed in $10 \%$ formaldehyde for $24 \mathrm{~h}$ at room temperature, washed and dehydrated with increasing gradient of ethanol (70\% for $2-4 \mathrm{~h}, 80 \%$ for $2-4 \mathrm{~h}$, $95 \%$ for $2-4 \mathrm{~h}$ and $100 \%$ for $1-2 \mathrm{~h}$ ), and washed with xylene for $30 \mathrm{~min}$ to $2 \mathrm{~h}$. Samples ( $3 \mu \mathrm{m}$ thick) were then embedded in paraffin and the lymph node slices were stained with hematoxylin and eosin (H\&E) for $50 \mathrm{~min}$ at room temperature prior to IHC analysis. SLNs were incubated with the wide-spectrum horn cytokeratin AEl/AE3 (no. M351501-2; Dako; Agilent Technologies, Inc.) for expression in the cytoplasm, which was detected using the two-step anti-rabbit/mouse universal IHC kit (no. GK500705; Dako Agilent Technologies, Inc.).

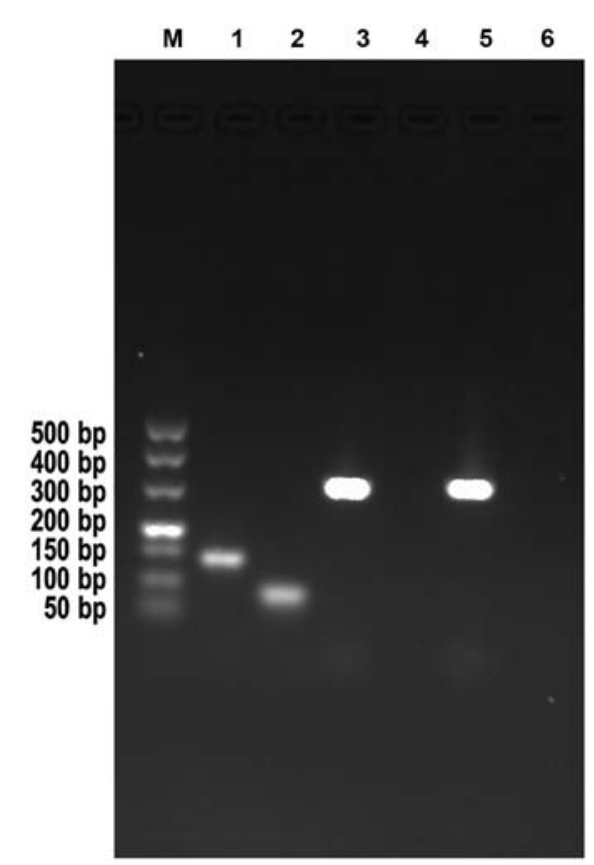

Figure 1. Electropherograms of HPV16 and HPV18 genes. Agarose gel electrophoresis results of PCR of HPV16/18 infection products in sentinel lymph nodes and negative control group. An HPV16/18 infection was observed in the sentinel lymph nodes. Lanes 1 and 2 present HPV16 infection products of sentinel lymph and HPV18 infection products, respectively. Lanes 3, 4, 5 and 6 present GAPDH of sentinel lymph node, HPV16 infection products of negative control group (normal cervical tissue was not infected with HPV16/18), GAPDH of negative control group and HPV18 infection products of negative control group, respectively. Lane M: DNA marker. HPV, human papilloma virus.

The criteria for the tumor cells were as follows: Large nucleus, deep staining, an imbalance of nucleo-cytoplasm ratio and AE1/AE3 is positive. The SLNs that were negative in pathology but HPV-DNA positive were further examined using an ultrastaging protocol (16). Two adjacent $5-\mu \mathrm{m}$ sections were cut at each of two levels $200 \mu \mathrm{m}$ apart. At each level, one slide was stained with $\mathrm{H} \& \mathrm{E}$ (20 $\mathrm{min}$ at room temperature) and the other was used for immunohistochemistry (IHC) using the anti-cytokeratin AE1:AE3 (1 h at room temperature). Sections were imaged using an optical microscope (OlympusBX45; Olympus Corporation; magnification, x100).

Statistical analysis. Statistical analysis was performed using SPSS software (IBM Corp.; version 22.0;). Standard summary statistics were used to describe primary data: Data were presented by the median values. The positive rate of lymph node metastasis was compared by $\chi^{2}$ test. The Mann-Whitney rank sum test of non-parametric data was used to compare the mean independent values of continuous variables. The association between discrete variables was determined by Fisher's exact test. $\mathrm{P}<0.05$ was considered to indicate a statistically significant difference.

\section{Results}

Patient basic information. The present study included 100 patients with $\mathrm{CC}$. The median age was 52 years (range 33-68 years) and the median body mass index was $22.42 \mathrm{~kg} / \mathrm{m}^{2}$ (range $15.60-27.64 \mathrm{~kg} / \mathrm{m}^{2}$ ). There were a total of 78 cases of squamous cell carcinoma, 20 cases of adenocarcinoma, two 
A
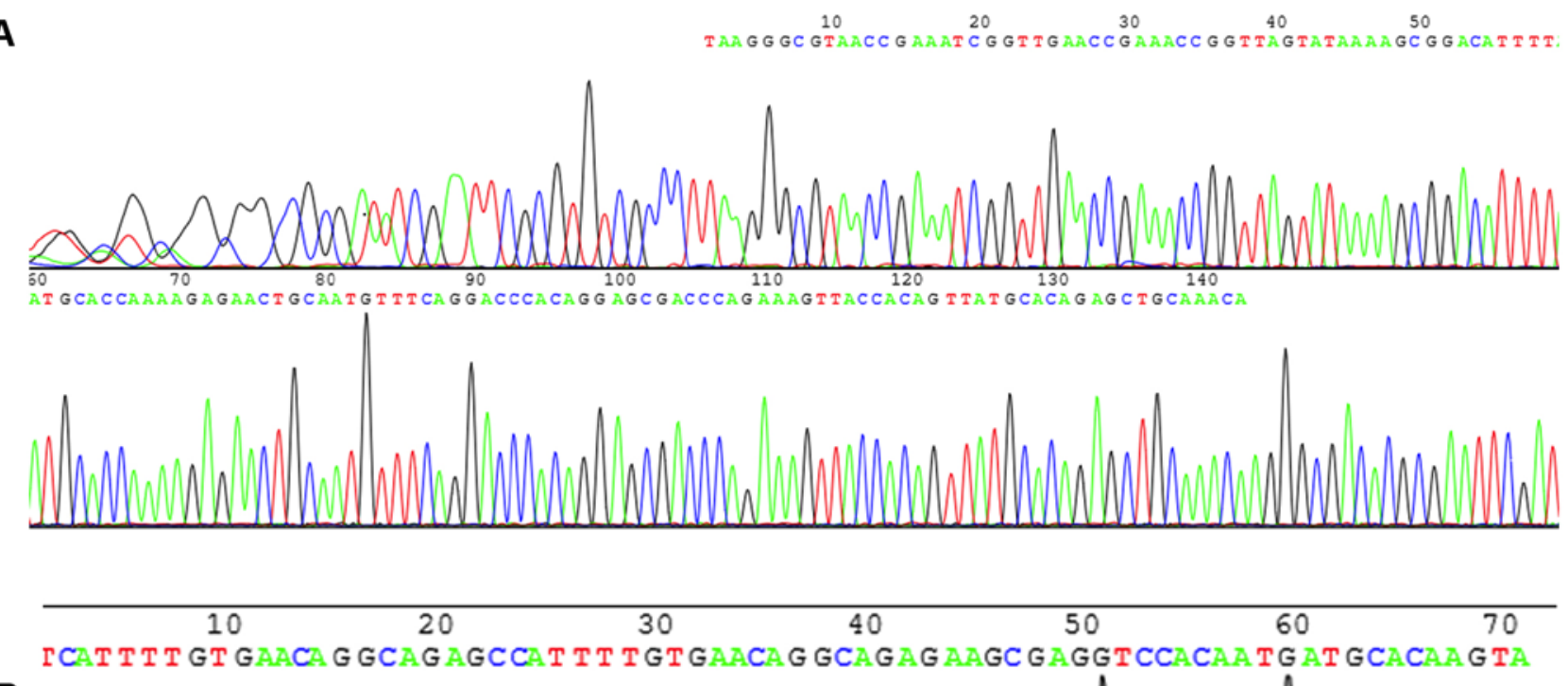

B

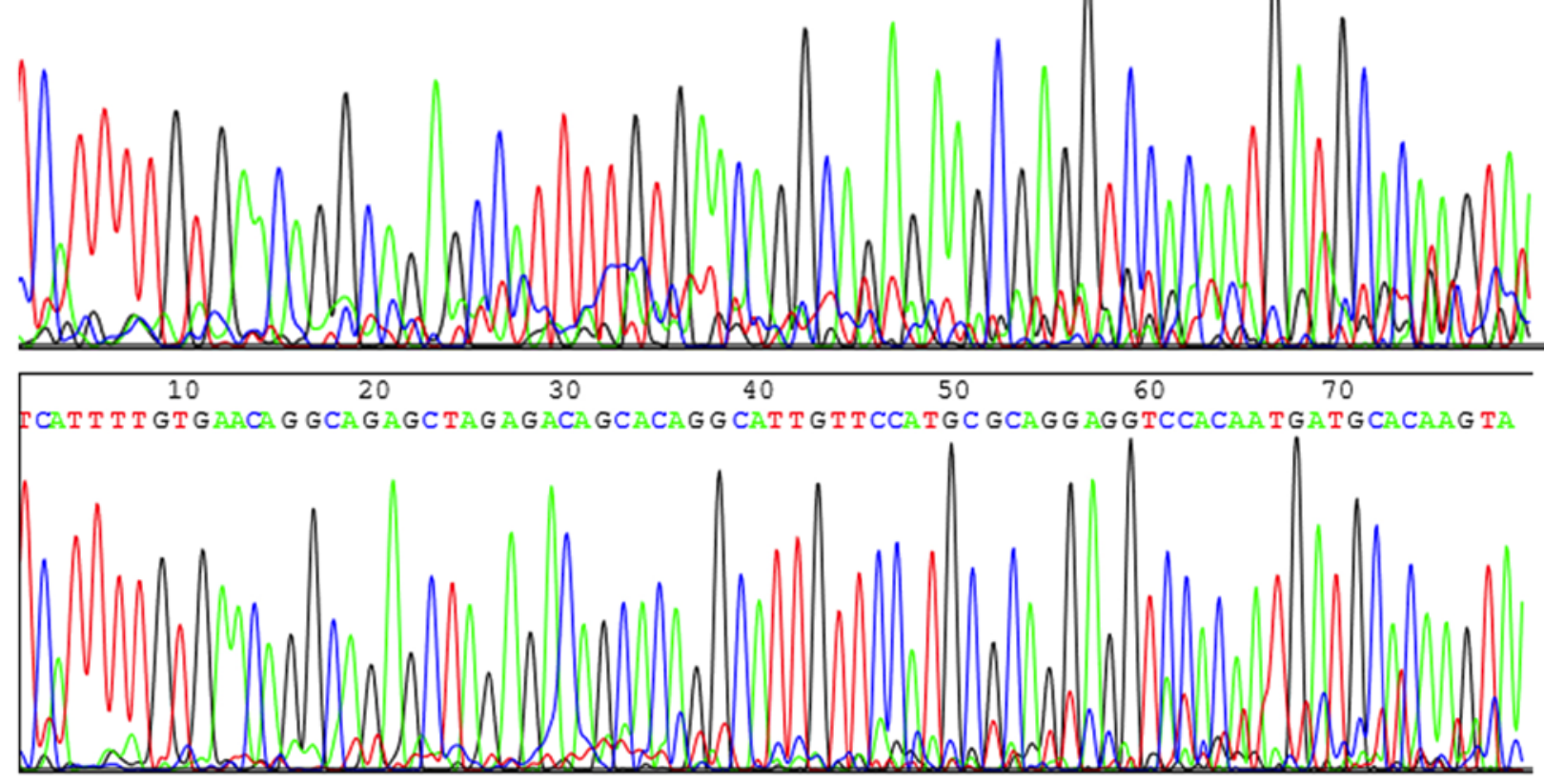

Figure 2. Sequencing of (A) HPV16 and (B) HPV18 PCR products. (A) Part of the whole sequencing of HPV16. (B) Part of the whole sequencing of HPV18.

cases of adenosquamous carcinoma, 51 cases of grade 3 (G3), 27 cases of moderate differentiation, eight cases of high differentiation and 14 unclassified cases. Additionally, there were zero cases with IA 2 stage, 32 cases with IB1 stage, 24 cases with IB2 stage, 21 cases with stage IIA1 and 23 cases with stage IIA2 CC. The tumor diameter was $\leq 2 \mathrm{~cm}$ in 19 cases, $2-4 \mathrm{~cm}$ in 45 cases and $>4 \mathrm{~cm}$ in 36 cases. In the 36 cases where the tumor lesions were $>4 \mathrm{~cm}$, paclitaxel + oxaliplatin neoadjuvant chemotherapy was administrated over 1-2 courses. Furthermore, there were 28 cases of cervical stromal invasion $<1 / 3,30$ cases of $1 / 3-2 / 3$, 42 cases of $>2 / 3,30$ cases of Lymphovascular Space Invasion (LVSI) positive, 92 cases of HPV positive and 8 cases of HPV negative. There were 1,680 lymph node dissections, including 345 SLNs and 1,335 nSLNs (Table I).

Electrophoresis and amplification curves of fluorescence qPCR amplification products. The results of agarose gel electrophoresis in the present study demonstrated that the HPV16 and HPV18 genes had a size of 141 and $80 \mathrm{bp}$, respectively (Fig. 1). The sequencing of HPV16 and HPV18 was a part of the whole sequencing presented in Fig. 2. The results of the present study demonstrated that the amplified DNA sequence was the same when compared with GenBank HPV16 and HPV18. Sequencing was conducted by Sangon Biotech Co., Ltd. (Fig. 3), which further confirmed that the obtained target gene sequence was correct.

$H P V-D N A$ detection of primary tumor and SLN. Of the 100 patients, 92 cases were diagnosed HPV-DNA positive by cervical liquid-based cytology, whereby the positive rate was $92 \%$. HPV16 was the most common type, which was detected in 71 cases. Of these, one case was mixed with HPV66, one case was mixed with HPV35 and one case was mixed with both HPV52 and HPV42. HPV18, HPV51, HPV33 and HPV59-DNA were detected in 13, four, two and two cases, respectively. Furthermore, two cases were mixed with HPV16 and HPV18. The lymph 


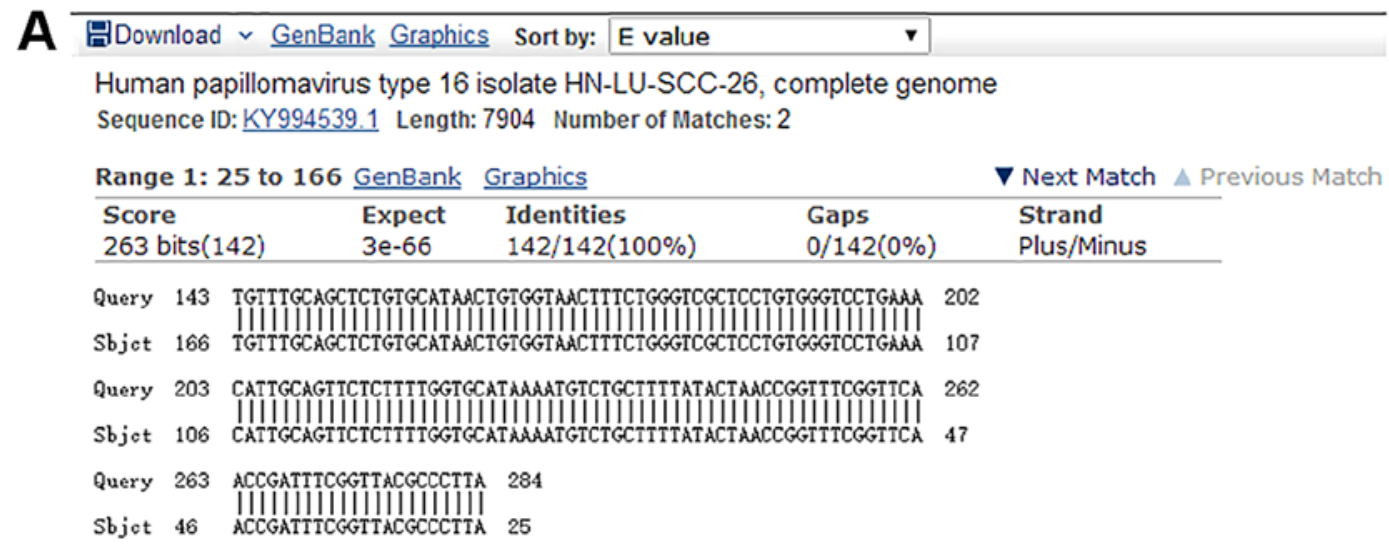

B Human papillomavirus type 18 isolate C387957_R1_1124102_N-P, complete genome Sequence ID: MF288722.1 Length: 7857 Number of Matches: 1

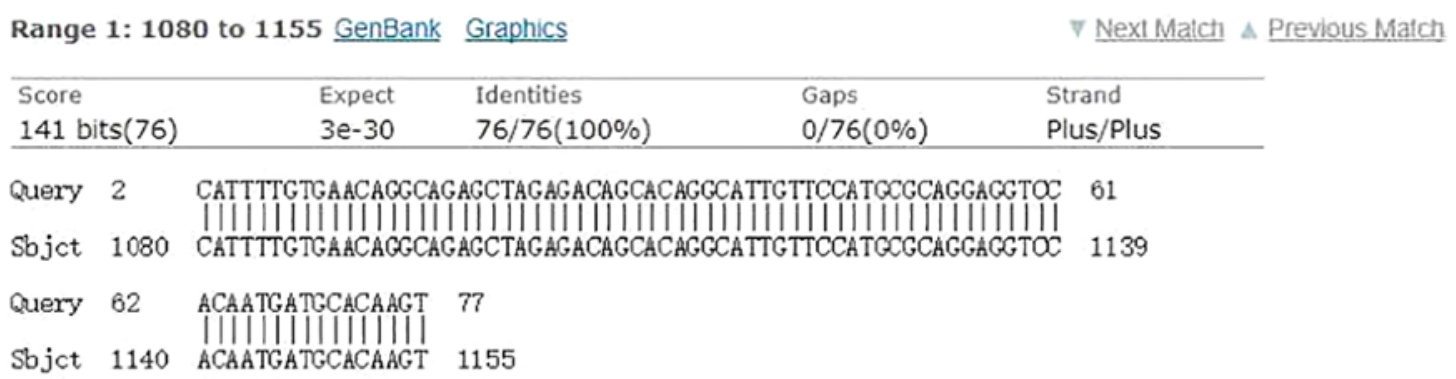

Figure 3. Sequencing of (A) HPV16 and (B) HPV18 in GeneBank. (A) HPV 16 sequence in GeneBank. (B) HPV 18 sequence in GeneBank.

node metastasis was detected in 14 patients via routine pathological examination. In addition, the RT-qPCR demonstrated that 28 patients had HPV-DNA expression in SLNs, whereas 72 patients did not. Of those positive for HPV-DNA expression, 13 were HPV16 positive, nine were HPV18 positive and six were other positive (HPV66, 35, 52 and 45; Table II).

SLN histopathology. IHC analysis demonstrated positive staining of AEl/AE3 in the cytoplasm of cancer cells (Fig. 4B), which presented with a characteristic yellow-brown color, while no signal was observed in the SLN lymph nodes (Fig. 4A).

Expression of HPV-DNA in SLN and comparison with histopathological examination. The expression of HPV16/18 was positive in 109 SLNs in 28 patients; [positive rate was $31.6 \%$ (109/345)]. The histopathological examination demonstrated that there were 44 SLNs with metastasis in 14 cases [positive rate was $12.8 \%(44 / 345)]$; and the pathologically positive lymph nodes were also all positive for HPV16/18. Of the 301 negative lymph nodes confirmed by pathological histology, the expression of HPV16/18 was positive in 65 SLNs [positive rate was $21.6 \%(65 / 301)](\mathrm{P}<0.001)$. Of the 14 patients with positive histopathology, the detection rate of HPV16/18 DNA was $100 \%$ (14/14), of which, HPV16 accounted for $71.4 \%(10 / 14)$ and HPV18 for $28.6 \%$ (4/14). In the 86 patients (301 lymph nodes) with negative histopathology, the detection rate of HPV16/18 DNA was $21.6 \%(65 / 301)$, while the detection rates of HPV16 and HPV18 were $20.6 \%(62 / 301)$ and $1.7 \%(5 / 301)$, respectively. HPV16 and HPV18 were simultaneously positive in five (1.7\%) lymph nodes. In addition, ultrastaging was
Table II. Status of HPV-DNA in SLNs.

\begin{tabular}{lccc}
\hline HPV type & SLN positive & SLN negative & Total \\
\hline HPV16 & 13 & 45 & 58 \\
HPV18 & 9 & 13 & 22 \\
Other & 6 & 14 & 20 \\
\hline
\end{tabular}

HPV, human papilloma virus; SLN, sentinel lymph node.

performed on all SLNs negative with H\&E staining, which detected micrometastases in 13 of the 14 patients (Table III).

A total of 345 SLNs were surgically removed, of which 44 were positive and 301 were negative. The median detection of HPV-DNA of the negative SLNs was 2.50 (1.90-2.90) copies/ng, while the median examination of HPV-DNA of the positive SLNs were 8.55 (6.20-9.80) copies/ng (Fig. 5; $\mathrm{Z}=-5.823, \mathrm{P}<0.001)$.

Association between the positive expression of HPV-DNA in SLN and clinical pathological factors. According to the clinicopathological features of the patients, numerous factors were selected to evaluate the association between positive expression of HPV-DNA and SLNs. The results of the present study demonstrated that the positive expression of HPV-DNA in SLN was significantly associated with clinical stage $(\mathrm{P}<0.001)$. Progression in the clinical stage was associated with an increase in tumor size and a greater possibility 

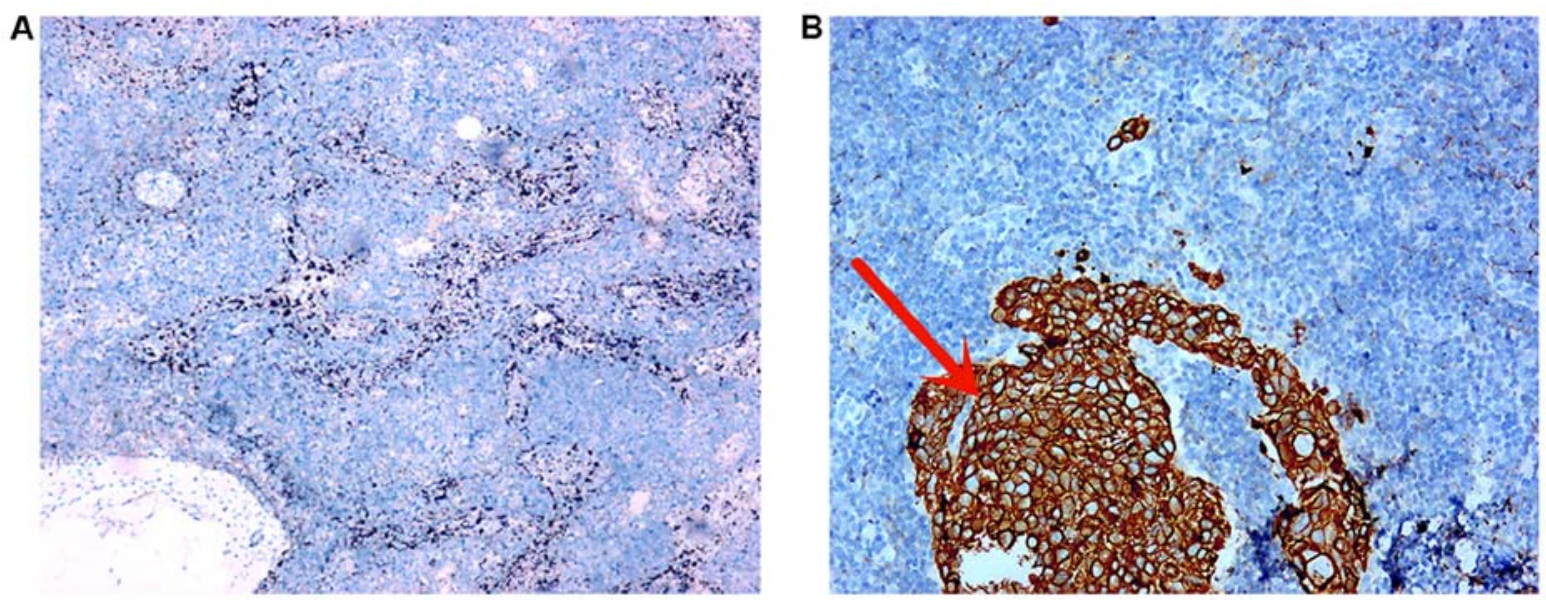

Figure 4. SLN pathological examination. (A) SLN pathological negative (H\&E; magnification, x200) (B) SLN pathological positive (H\&E; magnification, $\mathrm{x} 100$ ). Positivity was presented yellow-brown staining (red arrow). H\&E, hematoxylin and eosin.

Table III. Comparison of positive rate of lymph node detection by RT-qPCR and pathology.

\begin{tabular}{lrrccc}
\hline & \multicolumn{2}{c}{ SLN } & & & \\
\cline { 2 - 3 } Method & + & - & Total & $\chi^{2}$ & P-value \\
\hline Pathology & 44 & 301 & 345 & 35.482 & $<0.001$ \\
RT-PCR & 109 & 236 & 345 & & \\
\hline
\end{tabular}

SLN, sentinel lymph node; RT-qPCR, reverse transcription-quantitative PCR.

of metastasis $(\mathrm{P}=0.010)$. Nevertheless, the positive expression of HPV-DNA in SLN was not associated with age of patient, depth of cervical invasion, histological grade, lymphatic or LVSI, SCCAg (P>0.05; Table IV).

\section{Discussion}

The metastasis of tumor cells through lymphatic vessels to distant lymph nodes is considered the main adverse factor affecting the prognosis of CC (17). Nevertheless, local or distant recurrence may occur decades after treatment of the primary lesion in up to $15 \%$ of patients with early stage CC [patients without lymph node metastasis (pN0)]. This event may occur due to the proliferation of occult tumor cells and the existence of lymph node micrometastasis that are not readily detected by conventional pathology. The detection of micrometastasis of lymph nodes requires highly specific biomarkers, such as cytokeratin, SCC and HPV. However, IHC or cytokeratin are considered less specific (3-6). Dürst et al (13) demonstrated that HPV16-E6-E7-mRNA was more sensitive and specific than cytokeratin-(CK)19-mRNA for the detection of disseminated tumor cells in SLNs. HR-HPV persistent infection is one of the most important risk factors for $\mathrm{CC}$, but also for several other types of cancer, including head and neck, vaginal, vulva, penile and anal cancer (18). In addition, previous studies have demonstrated that the presence of HPV is associated with the prognosis of patients after radiotherapy or concurrent radiochemotherapy, while the pelvic lymph node of HPV is associated with an increased risk of recurrence (19-21). HPV DNA was chosen as a molecular marker for the detection of tumor cells in SLN shown to be negative by conventional histopathology, by using specific primers of HPV16 and HPV18.

The Cancer Genome Atlas Research Network (22) has suggested that $95 \%$ of primary CC are HPV positive. In addition, $<10 \%$ of invasive $\mathrm{CC}$ cases are classified as 'HPV negative', using the standard test for HR subtypes (23-25). HPV screening is more sensitive than cytological screening in detecting high-grade neoplasia (26). Based on this evidence, the new guidelines in Europe, Australia and the USA have now recommended HPV screening for all women aged $\geq 30$ (27-29). In addition, the HPV-DNA has been proposed as a potential biomarker for tumor metastasis associated with HPV (4). To date, a number of studies $(9,21,30)$ have attempted to investigate the association between HR-HPV DNA detection in lymph nodes, lymph node metastasis and the prognosis of patients with CC. In a previous study, the safety of SLN mapping was demonstrated as well as how SLN can represent the status of pelvic lymph nodes (31). It is known that in early stage CC, if SLN do not exhibit metastasis, then neither do other lymph nodes (31). Therefore, the detection of HPV-DNA expression in SLN also suggests the expression status of pelvic lymph nodes.

The detection of HPV-DNA in CC has been reported in both ThinPrep cytology test and plasma (32). Lancaster et al (33) first proposed the use of HPV-DNA for the detection of CC metastasis. They revealed that these metastatic tumors carry the same HR-HPV type as the primary tumor. But the results of published data are not the same (34). Considering that HPV-DNA is usually integrated into the genome of host cancer cells, it can be used as a sensitive biomarker for the detection of micrometastasis (34). Furthermore, it can be used to investigate the potential spread of single tumor cells, particularly when pathological indications for the surgical margin and lymph nodes are negative (34). Tortora et al (35) examined 20 patients with primary $\mathrm{CC}$ and demonstrated that seven out of $20(35 \%)$ women had metastatic spread in peri-tumor tissues and/or lymph nodes, as determined by histology. In 
Table IV. Association between positive expressions of HPV-DNA and the clinical pathological factors in SLNs.

\begin{tabular}{|c|c|c|c|c|}
\hline Clinicopathological features & No. of cases, $\mathrm{n}$ & Positive & Positive rate, $\%$ & P-value \\
\hline Age & & & & 0.524 \\
\hline$\leq 40$ years & 6 & 1 & 16.67 & \\
\hline$>40$ years & 94 & 27 & 28.72 & \\
\hline Clinical stage & & & & $<0.001$ \\
\hline IA2 & 0 & 0 & 0 & \\
\hline IB1 & 32 & 1 & 3.12 & \\
\hline IB2 & 24 & 1 & 4.17 & \\
\hline IIA1 & 21 & 8 & 19.05 & \\
\hline IIA2 & 23 & 18 & 78.26 & \\
\hline Tumor size & & & & 0.010 \\
\hline$<2 \mathrm{~cm}$ & 19 & 9 & 47.37 & \\
\hline $2-4 \mathrm{~cm}$ & 45 & 15 & 33.33 & \\
\hline$>4 \mathrm{~cm}$ & 36 & 4 & 11.11 & \\
\hline Histological grade & & & & 0.148 \\
\hline G1 & 8 & 1 & 12.50 & \\
\hline $\mathrm{G} 2$ & 27 & 8 & 29.63 & \\
\hline G3 & 51 & 18 & 35.29 & \\
\hline NA & 14 & 1 & 7.14 & \\
\hline Depth of cervical stromal invasion & & & & 0.141 \\
\hline$<1 / 3$ & 28 & 4 & 14.28 & \\
\hline $1 / 3-2 / 3$ & 30 & 9 & 30.00 & \\
\hline$>2 / 3$ & 42 & 15 & 35.71 & \\
\hline LVSI & & & & 0.080 \\
\hline Positive & 30 & 12 & 40.00 & \\
\hline Negative & 70 & 16 & 22.85 & \\
\hline SCCAg & & & & 0.233 \\
\hline$\leq 1.5 \mu \mathrm{g} / 1$ & 27 & 6 & 22.22 & \\
\hline$>1.5 \mu \mathrm{g} / 1$ & 63 & 22 & 34.92 & \\
\hline
\end{tabular}

LVSI, Lymphovascular space invasion; SCCAg, squamous cell carcinoma antigens.

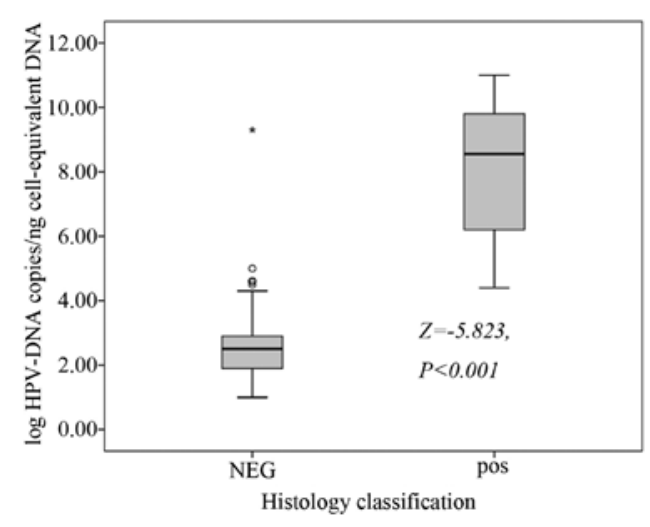

Figure 5. HPV expression of SLN. *Outlier. HPV, human papilloma virus; SLN, sentinel lymph nodes; NEG, SLN negative; POS, SLN positive.

addition, the HPV-DNA was detected in all histological positive samples as well as in 16 and $25 \%$ of histological negative peri-tumor tissues and lymph nodes, respectively. Furthermore, an evidence-based study (34), which included 1,333 patients with early stage $\mathrm{CC}$ who underwent pathological examination and HPV testing, demonstrated that expression of HPV-DNA is detected in $\sim 75 \%$ of the 488 patients with at least one lymph node metastasis. In the present study, the most common HPV type was HPV16, which was observed in 71 cases (77.2\%), followed by: Mixed HPV66 in one case, mixed HPV35 in one case, and mixed HPV52 and HPV45 in one case. In addition, there were 13 cases of HPV18 type (14.1\%), two cases of HPV16 and HPV18 mixed types $(2.1 \%$, four cases of HPV51 type $(4.3 \%)$, two cases of HPV33 type $(2.1 \%)$ and two cases of HPV59 type (2.1\%). The expression of HPV16 and HPV18 in lymph nodes was observed in 13 cases $(46.4 \%)$ and nine cases (32.1\%), respectively. HPV-DNA was detected in all patients with positive pathology. Dürst et al (13) reported that $60 \%$ of primary tumors were positive for HPV16 and 22\% for HPV18, and were also positive for HPV35, HPV45 and HPV73. HPV-mRNA expression in SLN was $27.5 \%$ positive, $63.0 \%$ negative and $9.5 \%$ possible negative was detected by PCR. To the best of our knowledge, Lukaszuk et al (8) performed the 
first prospective study on frozen fresh tissue of cervical lesions and pelvic lymph nodes, and demonstrated that HPV-DNA in lymph nodes was an independent tumor risk factor associated with survival rate and mortality. Furthermore, Dürst et al (13) evaluated the expression of HPV E6/E7 mRNA as a molecular biomarker in negative sentinel lymph nodes and demonstrated that HPV-mRNA was detected in $27.5 \%$ of patients with SLN, while 22 patients exhibited recurrence. In addition, patients that were HPV-mRNA negative in SLN had significantly longer tumor-free survival $(\mathrm{P}=0.002)$. Furthermore, the Cox regression analysis hazard ratio $(95 \% \mathrm{CI})$ for disease-recurrence was 3.8 (1.5-9.3; $\mathrm{P}=0.004)$ for HPV-mRNA-positive compared with HPV-mRNA-negative patients. Dürst et al (13) suggested that HPV-mRNA positive SLN has prognostic value independent of tumor size, particularly for tumors $>20 \mathrm{~mm}$ in diameter. Further risk stratification using HPV-mRNA as a molecular biomarker may benefit patients. The present study further evaluated the expression of HPV E6/E7 mRNA in lymph nodes (not in SLNs) and analyzed the prognosis (13). In addition to evaluating the expression of HPV-DNA in SLNs, the present study also compared pathological results to verify whether there was micrometastasis in lymph nodes with negative pathology but positive HPV-DNA expression. Furthermore, the sensitivity of HPV-DNA expression in SLN was compared with routine pathology (13). Köhler et al (36) demonstrated that histologically confirmed metastatic lymph nodes were also HPV E6/E7 mRNA positive, resulting in a sensitivity of $100 \%$. A total of four histologically free sentinel nodes were positive for HPV E6/E7 mRNA, resulting in a specificity of $96.4 \%$. The HPV E6/E7 mRNA assay in the SLNs of patients with CC was feasible and highly accurate. The detection of HPV mRNA with negative SLNs may denote a shift from microscopic identification of metastasis to the molecular level. In the present study, a total of 28 cases of 109 SLNs, detected by RT-qPCR, were HPV16/18 positive, with a positive rate of $31.6 \%(109 / 345)$. Nevertheless, only 14 patients with a total of 44 SLNs metastases were detected by traditional histopathological methods, with a positive rate of $12.8 \%$ (44/345) $(\mathrm{P}<0.001)$. HPV16/18 were all positive in the histologically positive nodes. Among the 301 SLNs with pathological negative, 65 SLNs were positive for HPV16/18 (21.6\%). The results of the present study suggest that pathologically negative, but high levels of HPV-DNA expression, may indicate an early and significant risk of lymphatic tumor metastasis. In terms of post-operative treatment, pathologically negative lymph nodes with high load HPV-DNA positive may need to be treated with adjuvant treatment to decrease the risk of distant disease recurrence (37). In addition, the present study demonstrated that the HPV-DNA in SLNs was associated with clinical stage and tumor size $(\mathrm{P}<0.05)$, but not with the age of the patient, depth of cervical invasion, histological grade, LVSI and SCCAg $(\mathrm{P}>0.05)$. To the best of our knowledge, there are currently no data published.

The main limitation of the present study was the short follow-up time. In addition, the associations between recurrence rate, mortality and HPV-DNA positive expression in SLN were not evaluated.

Overall, the results of the present study suggest that detection of HPV-DNA expression in SLN has a higher positive rate than histopathology. The high load of HPV-DNA in lymph nodes can provide additional evidence of metastasis, while its quantification may be used as a useful clinical biomarker. For patients with negative lymph nodes, HPV-DNA detection may have the potential to guide surveillance. In addition, HPV-DNA positive patients will require closer surveillance than HPV-DNA negative patients.

\section{Acknowledgements}

Not applicable.

\section{Funding}

The present study was funded by the Development and Application of Appropriate Medical and Health Technology in GuangXi (grant no. S2017100) and GuangXi Key Research and Development Plan Fund (grant no. AB17292092). The funding body had no further role in the collection, review or publication of the data presented in this article.

\section{Availability of data and materials}

The datasets used and/or analyzed during the current study are available from the corresponding author on reasonable request.

\section{Authors' contributions}

YL and DY conceived and designed the study. YL, XX and XN wrote the manuscript. YL, XX and XN performed HPV expression analysis, and prepared figures and tables. YL, XX and DY interpreted the results. YL and XX revised the manuscript. All authors read and approved the final version of the manuscript.

\section{Ethics approval and consent to participate}

The present study was approved by The Medical Ethics Committee of Guangxi Medical University Affiliated Tumor Hospital (registration number: LW2018028). Written consent was obtained from all patients prior to sample collection.

\section{Patient consent for publication}

Not applicable.

\section{Competing interests}

The authors declare that they have no competing interests.

\section{References}

1. Delgado G, Bundy BN, Fowler WC Jr, Stehman FB, Sevin B, Creasman WT, Major F, DiSaia P and Zaino R: A prospective surgical pathological study of stage I squamous carcinoma of the cervix: A gynecologic oncology group study. Gynecol Oncol 35: 314-320, 1989.

2. Slama J, Dundr P, Dusek L and Cibula D: High false negative rate of frozen section examination of sentinel lymph nodes in patients with cervical cancer. Gynecol Oncol 129: 384-388, 2013.

3. Lentz SE, Muderspach LI, Felix JC, Ye W, Groshen S and Amezcua CA: Identification of micrometastases in histologically negative lymph nodes of early-stage cervical cancer patients. Obstet Gynecol 103: 1204-1210, 2004. 
4. Okamoto S, Niikura H, Nakabayashi K, Hiyama K, Matoda M, Takeshima N, Watanabe M, Nagase S, Otsuki T and Yaegashi N: Detection of sentinel lymph node metastases in cervical cancer: Assessment of KRT19 mRNA in the one-step nucleic acid amplification (OSNA) method. Gynecol Oncol 130: 530-536, 2013.

5. Huang BX and Fang F: Progress in the study of lymph node metastasis in early-stage cervical cancer. Curr Med Sci 38 : 567-574, 2018

6. Bostick PJ, Chatterjee S, Chi DD, Huynh KT, Giuliano AE, Cote R and Hoon DS: Limitations of specific reverse-transcriptase polymerase chain reaction markers in the detection of metastases in the lymph nodes and blood of breast cancer patients. J Clin Oncol 16: 2632-2640, 1998

7. Van Trappen PO, Gyselman VG, Lowe DG, Ryan A, Oram DH, Bosze P, Weekes AR, Shepherd JH, Dorudi S, Bustin SA and Jacobs IJ: Molecular quantification and mapping of lymph-node micrometastases in cervical cancer. Lancet 357 $15-20,2001$.

8. Lukaszuk K, Liss J, Gulczynski J, Nowaczyk M, Nakonieczny M, Piatkowski M, Sliwinski W, Baay M, Wozniak I, Maj B and Lukaszuk M: Predictive value of HPV DNA in lymph nodes in surgically treated cervical carcinoma patients-a prospective study. Gynecol Oncol 104: 721-726, 2007.

9. Carow K, Read C, Häfner N, Runnebaum IB, Corner A and Dürst M: A comparative study of digital PCR and real-time qPCR for the detection and quantification of HPV mRNA in sentinel lymph nodes of cervical cancer patients. BMC Res Notes 10: 532, 2017

10. Petry KU, Liebrich C, Luyten A, Zander M and Iftner T: Surgical staging identified false HPV-negative cases in a large series of invasive cervical cancers. Papillomavirus Res 4: 85-89, 2017.

11. Coutant C, Barranger E, Cortez A, Dabit D, Uzan S, Bernaudin JF and Darai E: Frequency and prognostic significance of HPV DNA in sentinel lymph nodes of patients with cervical cancer. Ann Oncol 18: 1513-1517, 2007.

12. Slama J, Drazdakova M, Dundr P, Fischerova D, Zikan M, Pinkavova I, Freitag P, Fanta M, Kuzel D, Zima T and Cibula D: High-risk human papillomavirus DNA in paraaortic lymph nodes in advanced stages of cervical carcinoma. J Clin Virol 50: 46-49, 2011.

13. Dürst $M$, Hoyer H, Altgassen $C$, Greinke $C$, Häfner $N$, Fishta A, Gajda M, Mahnert U, Hillemanns P, Dimpfl T, et al: Prognostic value of HPV-mRNA in sentinel lymph nodes of cervical cancer patients with pN0-status. Oncotarget 6 : 23015-23025, 2015.

14. Bhatla N, AokiD, Sharma DN and Sankaranarayanan R: FIGOCancer Report 2018. Int J Gynecol Obstet 143 (Suppl 2): S22-S36, 2018.

15. Kawase J, Asakura H, Kurosaki M, Oshiro H, Etoh Y, Ikeda T, Watahiki M, Kameyama M, Hayashi F, Kawakami Y, et al: Rapid and accurate diagnosis based on real-time PCR cycle threshold value for the identification of campylobacter jejuni, ast $A$ gene-positive escherichia coli, and eae gene-positive E. coli. Jpn J Infect Dis 71: 79-84, 2018.

16. Cibula D, Zikana M, Slama J, Fischerova D, Kocian R Germanova A, Burgetova A, Dusek L, Dundr P, Gregova M and Nemejcova K: Risk of micrometastases in non-sentinel pelvic lymph nodes in cervical cancer. Gynecol Oncol 143 83-86, 2016.

17. Wiebe E, Denny L and Thomas G: Cancer of the cervix uteri. Int J Gynaecol Obstet 119 (Suppl 2): S100-S109, 2012.

18. Doorbar J, Egawa N, Griffin H, Kranjec C and Murakami I: Human papillomavirus molecular biology and disease association. Rev Med Virol 25 (Suppl 1): S2-S23, 2015.

19. Biesaga B, Janecka A, Mucha-Małecka A, Adamczyk A Szostek S, Słonina D, Halaszka K and Przewoźnik M: HPV16 detection by qPCR method in relation to quantity and quality of DNA extracted from archival formalin fixed and paraffin embedded head and neck cancer tissues by three commercially available kits. J Virol Methods 236: 157-163, 2016.

20. Schroeder L, Boscolo-Rizzo P, Dal Cin E, Romeo S, Baboci L, Dyckhoff G, Hess J, Lucena-Porcel C, Byl A, Becker N, et al: Human papillomavirus as prognostic marker with rising prevalence in neck squamous cell carcinoma of unknown primary: A retrospective multicentre study. Eur J Cancer 74: 73-81, 2017.

21. Fuglsang K, Blaakaer J, Petersen LK, Mejlgaard E, Hammer A and Steiniche T: Detection of high-risk human papillomavirus DNA in tissue from primary cervical cancer tumor, pelvic lymph nodes and recurrent disease. Papillomavirus Res 7: 15-20, 2019.
22. Cancer Genome Atlas Research Network; Albert Einstein College of Medicine; Analytical Biological Services; Barretos Cancer Hospital; Baylor College of Medicine; Beckman Research Institute of City of Hope; Buck Institute for Research on Aging; Canada's Michael Smith Genome Sciences Centre; Harvard Medical School; Helen F. Graham Cancer Center \&Research Institute at Christiana Care Health Services, et al: Integrated genomic and molecular characterization of cervical cancer. Nature 543: 378-384, 2017.

23. Arbyn M, Tommasino M, Depuydt C and Dillner J: Are 20 human papillomavirus types causing cervical cancer? J Pathol 234: 431-435, 2014.

24. Hopenhayn C, Christian A, Christian WJ, Watson M, Unger ER, Lynch CF, Peters ES, Wilkinson EJ, Huang Y, Copeland G, et al: Prevalence of human papillomavirus types in invasive cervical cancers from 7 US cancer registries before vaccine introduction. J Low Genit Tract Dis 18: 182-189, 2014.

25. Mbatani N, Adams T, Wijk LV, Behrens C, Tam T, Wright T Jr, Stoler M and Denny L: Performance of an human papillomavirus test in samples from women with histolopathologically confirmed invasive cervical cancer. J Low Genit Tract Dis 20: 151-153, 2016.

26. Ronco G, Dillner J, Elfström KM, Tunesi S, Snijders PJ, Arbyn M, Kitchener H, Segnan N, Gilham C, Giorgi-Rossi P, et al: Efficacy of HPV-based screening for prevention of invasive cervical cancer: Follow-up of four European randomised controlled trials. Lancet 383: 524-532, 2014.

27. Armaroli P, Villain P, Suonio E, Almonte M, Anttila A, Atkin WS, Dean PB, de Koning HJ, Dillner L, Herrero R, et al: European code against cancer, 4th edition: Cancer screening. Cancer Epidemiol 39 (Suppl 1): S139-S152, 2015.

28. Carter J, Hammond I and Smith M: The renewal of the national cervical screening program. Med J Aust 206: 274, 2017.

29. Sawaya GF, Kulasingam S, Denberg TD and Qaseem A; Clinical Guidelines Committee of American College of Physicians: Cervical cancer screening in average-risk women: Best practice advice from the clinical guidelines committee of the American college of physicians. Ann Intern Med 162: 851-859, 2015.

30. Zhang F, Liu D, Lin B, Hao Y, Zhou D, Qi Y and Zhang S: Expression of high-risk HPV DNA and CK19 in pelvic lymph nodes in stage Ia-IIa cervical cancer and their clinical value. Oncol Rep 27: 1801-1806, 2012.

31. Lu Y, Wei JY, Yao DS, Pan ZM and Yao Y: Application of carbon nanoparticles in laparoscopic sentinel lymph node detection in patients with early-stage cervical cancer. PLoS One 12: e0183834, 2017.

32. Duvlis S, Popovska-Jankovic K, Arsova ZS, Memeti S, Popeska Z and Plaseska-Karanfilska D: HPV E6/E7 mRNA versus HPV DNA biomarker in cervical cancer screening of a group of Macedonian women. J Med Virol 87: 1578-1586, 2015.

33. Lancaster WD, Castellano C, Santos C, Delgado G, Kurman RJ and Jenson AB: Human papillomavirus deoxyribonucleic acid in cervical carcinoma from primary and metastatic sites. Am J Obstet Gynecol 154: 115-119, 1986.

34. Noventa M, Ancona E, Cosmi E, Saccardi C, Litta P, D'Antona D, Nardelli GB and Gizzo S: Usefulness, methods and rationale of lymph nodes HPV-DNA investigation in estimating risk of early stage cervical cancer recurrence: A systematic literature review. Clin Exp Metastasis 31: 853-867, 2014.

35. Tortora M, Annunziata C, Liguori G, Losito S, Botti G, Greggi S, Buonaguro L, Buonaguro FM and Tornesello ML: Detection of human papillomavirus DNA in peri-tumor tissues and pelvic lymph nodes as potential molecular marker of micrometastasis in cervical cancer. Infect Agent Cancer 11: 22, 2016.

36. Köhler C, Le X, Dogan NU, Pfiffer T, Schneider A, Marnitz S, Bertolini J and Favero G: Molecular diagnosis for nodal metastasis in endoscopically managed cervical cancer: The accuracy of the APTIMA test to detect high-risk human papillomavirus messenger RNA in sentinel lymph nodes. J Minim Invasive Gynecol 23: 748-752, 2016.

37. Lillo F, Galli L, Lodini S, Taccagni G, Ferrari A and Origoni M: Extralesional detection and load of human papillomavirus DNA: A possible marker of preclinical tumor spread in cervical cancer. J Low Genit Tract Dis 12: 204-209, 2008

This work is licensed under a Creative Commons Attribution-NonCommercial-NoDerivatives 4.0 International (CC BY-NC-ND 4.0) License. 